\title{
Brown Seaweed Sargassum Cinereum Extract Ameliorates the Hepato and Nephrotoxicity induced by Cyclophosphamide in Male Albino Rats: Hematological Biochemical and histobiochemical examinations
}

\author{
Atef M. Khalil ${ }^{1 *}$, Naglaa R. A. Kasem ${ }^{2}$, Azza S. A. Ali ${ }^{2}$ and Muhammad M. A. Salman ${ }^{2}$ \\ ${ }^{1}$ Pathology and Clinical Pathology Department, Faculty of Veterinary Medicine, South Valley University, 83523 Qena, Egypt \\ ${ }^{2}$ Zoo Department, Faculty of Science; South Valley University, 83523, Qena, Egypt
}

DOI: $10.36348 /$ sjpm.2020.v05i02.009

| Received: 05.02.2020 | Accepted: 12.02.2020 | Published: 16.02.2020

*Corresponding author: Atef Mohammed Hussien Khali

\section{Abstract}

Background: Cyclophosphamide (CP) is a selective antibiotic used clinically as an anticancer drug. Treatment with $\mathrm{CP}$ exhibits a number of side effects. Here in this study, we explored the toxic effects of $\mathrm{CP}$ and the ameliorating effects of Sargassum cinereum in albino rats. Material and methods: Eighteen rats divided into 3 groups (6 rats each) control group, CP injected group in a dose of $200 \mathrm{mg} / \mathrm{kg} \mathrm{b}$. w and CP injected plus oral administration of S. cinereum group in a dose of $180 \mathrm{mg} / \mathrm{kg} \mathrm{b}$. w for 20 consecutive days. Results showed cyclophosphamides induced hematological, biochemical, oxidative and histological changes. Results: Hematological analyses revealed a significant decrease in the RBCs, WBCs' count and Hb concentration. Biochemical analyses revealed increase in the liver enzymes activityincluding ALT, AST and ALP, while albumin and total proteins were significantly decreased. Creatinine, urea, and uric acid levels as well as lipid profiles including cholesterol and triglycerides were increased signifcantly. Moreover, Oxidative stress was active that evidenced by a significant decrease in SOD, GSH and CAT levels, while a significant increase was recorded in the MDA level. For histopathology necrosis and inflammations were oserved in the hepatic and kidney tissues. Treatment with brown seaweed S.cinierium significantly ameliorated all of the above mentioned hematological, biochemical, oxidative damages and histopathological changes induced by CP injection. Conclusion: Cyclophosphamide induced its toxicity throught the activation of the oxidative system in the tissues, while the ameliorative effect of brown seweeds (S. cinereum) achived throught activation the antioxidant system.

Keywords: Biochemicals, Cyclophosphamides, Hepatitis, Histopathological, Oxidative stress, S. cinereum.

Copyright @ 2020: This is an open-access article distributed under the terms of the Creative Commons Attribution license which permits unrestricted
use, distribution, and reproduction in any medium for non-commercial use (NonCommercial, or CC-BY-NC) provided the original author and sources
are credited.

\section{INTRODUCTION}

Cyclophosphamide (CP) and the associated nitrogen mustard-derived alkylating agents are widely used in the treatment of a variety of human malignancies and disorders like breast cancer, carcinoma of the lung [1], systemic lupus erythematosus, rheumatoid arthritis and multiple sclerosis [2,3]. Unfortunately, the use of this drug is accompanied by a number of side effects and toxicity that includes nausea, vomiting, alopecia [4], hematopoietic suppression [5], nephrotoxicity, urotoxicity [6] and cardiotoxicity [7]. The highly toxic effect of $\mathrm{CP}$ mediated through the activation of cytochrome P450 enzyme which enhance the oxidation process with the synthsis of the toxic products phosphoramide mustard and acrolein [8]. In this pathway of $\mathrm{CP}$ ioactivation reactive oxygen species were have potentialy generated [9]. Oxidative stress is responsible for $\mathrm{CP}$ induced hepatotoxicity [10]. The report presented by $\mathrm{Al}$ zeni [11] revealed that $\mathrm{CP}$ treatment is associated with disrupt the liver function, evidinced by increases in AST, ALT, g-GT and CPK levels. Cyclophosphamides injection enhanced the oxidative stresssystem in the liver that marked by increased in the lipid peroxidation (LPO) and decreased the glutathione (GSH) content, glutathione peroxidase (GPx) as well as the superoxide dismutase (SOD) activities [12].

Several studies have shown that CP can be nephrotoxic, both in humans and in animal experimental models as it induced glomerular and tubular disfunction $[13,14]$. Besides fibrosis, necrosis of urinary bladder and hemorrhagic cystitis $[15,16]$.

Egypt country chractrized by long seashores such as in the Mediterranean and the Red Sea. These shores have a national wealth of marine organisms, 
especially algae. The large brown algae often play important roles in the physical and biological structure of the local marine environment [17]. Seaweeds are naturally renewable sources. They are used as food, feed, and fertilizers in diffrent regions in the world. Many studies and trials were done on seaweeds to isolate some life-saving drugs or biologically active compounds all over the world [18]. Sargassum sp., is one of the marine macroalgae amember of the class Phaeophyceae, family Sargassaceae and order Fucales and widely spread in tropical and temperate oceans. The brown seaweed Sargassum Cinereum is the great source of the biologically active sulfate and fucose compounds which they containing polysaccharide that considered as commercial antibiotics[19]. S. cinereum Ethanolic extract has medical uses as such as antibacterial, antifungal, antioxidative and radical scavenging activities [20]. This study was designated to investigate the toxic effects of the $\mathrm{CP}$ on the rats with a focus on the ameliorating effects of the $\mathrm{S}$. cinereum against the CP toxicity.

\section{MATERIALS AND METHODS Experimental Animals}

Eighteen (18) male White Albino rats 3-6 weeks age, (150-180 g) weight. The animals were purchased from the animal house, Faculty of Medicine, Assuit University, Egypt. Rats were housed in individual cages under a 12-h light/dark cycle. The room temperature and relative humidity were maintained at $23 \pm 1^{\circ} \mathrm{C}$ and $52 \%$, respectively. Rats were left for tow weeks before starting the experiment for the aclmitization. All animals were housed under the clean environmental conditions and given the basal diet and water ad-libitum. All protocols were approved by the Institutional Review Board for Animal Experiments of South Valley University, Egypt.

\section{Cyclophosphamides}

Cyclophosphamide (Endoxan) was supplied as vials from Baxter Oncology (Düsseldorf, Germany).

\section{Collection of Algal Samples}

The brown algae $S$. cinereum was collected from Hurghada city, Red Sea. The samples were cleaned with fresh water then distilled water. The samples dried under sunrise and then crushed to form a fine powder.

\section{Ethanolic extract of cinereum preparation}

The powdered seaweed $(100 \mathrm{~g})$ rinsed in 300 $\mathrm{ml}$ of $95 \%$ ethanol for 3 days at room temperature then poured out and filterated and repeated 2 times. The filtrates were evaporated at $40{ }^{\circ} \mathrm{C}$ under reduced pressure using a rotary evaporator to produce ethanolic crude extract [21].

\section{Experimental Design}

The experimental animals were randomly divided into three equal groups each of 6 animals.
Group 1: The rats were intraperitoneally injected with $0.9 \%$ isotonic saline solution at a dose of $5 \mathrm{ml} / \mathrm{kg} \mathrm{b} \mathrm{w}$. Group 2: The rats were intraperitoneally (i.p) injected with a single dose of cyclophosphamide (CP) 200 $\mathrm{mg} / \mathrm{kg} \mathrm{b}$. w. Group 3: The rats intraperitoneally injected with a single dose of cyclophosphamide (CP) 200 $\mathrm{mg} / \mathrm{kg} \mathrm{b}$. w plus oral administration of Sargassum cinereum extract at dose of $180 \mathrm{mg} / \mathrm{kg} \mathrm{b}$. W for consecutive 20 days.

At the end of experiment, all groups were sacrificed. Whole blood is collected by heart puncture and divided into 2 parts. The first one was put on heparinized tubes for hematological analyses. The other port was collected without anticoagulant for obtaining serum and kept frozen at $-20^{\circ} \mathrm{C}$ until used for biochemical analyses. Liver and kidney was removed aseptically and washed with phosphate buffered saline (PBS). Liver tissues were divided into two portions. First portion of liver tissue was blotted, homogenized using a Branson sonifier (250, VWR Scientific) and stored at $-80^{\circ} \mathrm{C}$ until used for determination of hepatic oxidative system (GSH, CAT, SOD, and MDA). The other portion both with kidney portion were kept in $10 \%$ buffered formaldehyde for histopathological inistigations.

\section{Hematological analysis}

The heparinized blood was used for assessment the RBCs' count, $\mathrm{Hb}$ concentration and WBCs' count using automated blood counter (Urit, China).

\section{Biochemical Assays}

Liver functions

Serum Alanine aminotransferase (ALT), aspartate aminotransferase, (AST) and alkaline phosphatase (ALP), Albumin and Total proteins were estimated using the available kits purchased from (spectrum Diagnostics Co. Oubor city. Egypt.) and analysed according to the manufacture procedures.

\section{Kidney functions}

Creatinine, urea and uric acid were estimated using the available kits purchased from (spectrum Diagnostics Co. Oubor city. Egypt), and analysed according to the manufacture rules.

\section{Liver Oxidative stress determination}

Different oxidative system markers Malondialdehyde(MDA), reduced glutathione(GSH), Catalase(CAT) and super oxide dismutase (SOD), were estimated in the liver homogenates using available kits purchased from (Bio-diagnostic Co. Giza. Egypt) and analyzed according the manufacture rules.

\section{Histopathology}

Collected liver and kidney tissues were rapidly fixed in $10 \%$ neutral buffered formalin, passed in ascending series of ethanol, embedded in paraffin for 
sectioning $(4-5 \mu \mathrm{m})$, then mounted on glass slides. Tissues sections were stained with Haematoxylin and Eosin (H\&E) for histopathological findings.

\section{Liver}

The liver tissues sections were scored according to Zhang [22] respectively histological activity index/scoring system, for the assessment of the following aspects 1) portal/ periportal activity with or without bridging necrosis grade $(0-10), 2)$ fibrosis grade (0-4). intralobular necrosis grade (0-4) 3) portal inflammation grade (0-4). The sum of the histological activity index of each lesion was multiplied by 2 to give more weight to this value.

\section{Kidneys}

The kidney tissues sections were scored according to Zhang [22] histological activity index/scoring system, for the assessment of the following aspects 1) normal histology grade (0), 2) tubular epithelial cell degeneration, without significant necrosis/apoptosis grade (1), 3) $25 \%, 50 \%, 75 \%$ and $75 \%$ of the tubules showing tubular epithelial cell necrosis/apoptosis grades $(2,3,4,5)$ respectively, Accompanied by other concomitant alterations.

\section{STATISTICAL ANALYSIS}

The results are expressed as mean \pm S.D. The means comparisons were made by using one-way analysis of variance (ANOVA) using Graph Pad Prism $03 \mathrm{n}$ software, where appropriate. Statistical significance was set at $\mathrm{p}<0.05$.

\section{RSULTS}

\section{Hematological analyses}

Intraperitoneal injection of Cyclophosphamide (CP) induced a significant decrease in the RBCs' count, WBCs, count and $\mathrm{Hb}$ concentration in group 2 and group 3 in comparison to group 1(normal animals). On the other hand, treatment with Sargassum Cinereum induced a significant increase in previous parameters when compared with group 2 as shown in Fig (1).

\section{Liver functions}

Injection of $\mathrm{CP}$ induced a significant increase in the liver enzymes activities (ALT, AST and ALP) associated with a significant decrease in total protein and albumin levels in group 2 and group 3 when in comparison with normal animals. Furthermore, treatment with S. cinereum, induced improvement in the enzymes activities and increased in the total protein and albumin levels in comparison with $\mathrm{CP}$ injected group according to Fig( 2 ).

\section{Kidney functions}

In the $\mathrm{CP}$ injected animals there is a significant increase in the kidney function tests( creatinine, urea and uric acid) levels of group 2 and 3 when compared with normal animals. Treatment with S. cinereum induced a significant decrease in these parameters in group 3 when compared with CP injected group Fig (3).

\section{Lipid profiles}

Fig.4, descried the effect of CP injection on the serum lipid profils as it induced significant increase in cholesterol and triglycerides levels with decrease in HDL- cholesterol in all groups in comparison to the normal group. Treatment with S. cinereum, exhibited a significant decrease in cholesterol and triglycerides levels, while HDL- cholesterol level was increased significantly when compared with the $\mathrm{CP}$ injected group.

\section{Liver homogenate biochemical oxidative stress}

As shown in Fig (5), injection of CP decreased the CAT, GSH and SOD concentration associated with a significant increase in MDA concentration in all groups when compared with group 1. In contrast, treatment with $\mathrm{S}$. cinereum induced a significant increase in CAT, GSH and SOD activities and decrease in MDA concentration in group 3 when compared with group 2 .

\section{RESULTS OF HISTOPATHOLOGY}

Histopathological injuries in the hepatic and renal tissues were induced due to $\mathrm{CP}$ injection. In Liver tissues as shown in Fig $(6 \mathrm{a}, \mathrm{b}$ and $\mathrm{c})$. The histopathological changes include periportal necrosis plus bridging necrosis. In the other hand treatment with $\mathrm{S}$. cinereum caused moderate necrosis involves $<50 \%$ of the circumference of most portal tracts without bridging necrosis. Furthermore, $\mathrm{CP}$ injection induced moderate inflammation characterized by inflammatory cells infiltration in $2 / 3$ of portal tracts while treatment with $\mathrm{S}$. cinereum induced mild inflammatory responses characterized by few inflammatory cells in $<1 / 3$ of portal tracts. Moreover, CP toxicity exhibited fibrous portal expansion while no fibrosis was recorded in $\mathrm{S}$. cinereum treated group. In the kidney, CP injection induced renal injury that manifested by sever necrosis in both renal tubules and renal glomeruli leading to their atrophy. Some inflammatory cells infiltrated around the severely injured tissue. Recovery in the renal tissue was achieved after S.cinerium administration, which characterized by decrease the necrotic tissues and inflammatory cells infiltration as shown in Fig( a, b, and c). Histology index score (HIS).

Injection of CP induced liver tissues damages confirmed by increase the total of histology index score, which recovered by oral administration of $S$. cinereum and evidenced by decrease in the total of histology index score as shown in Fig (4d). 

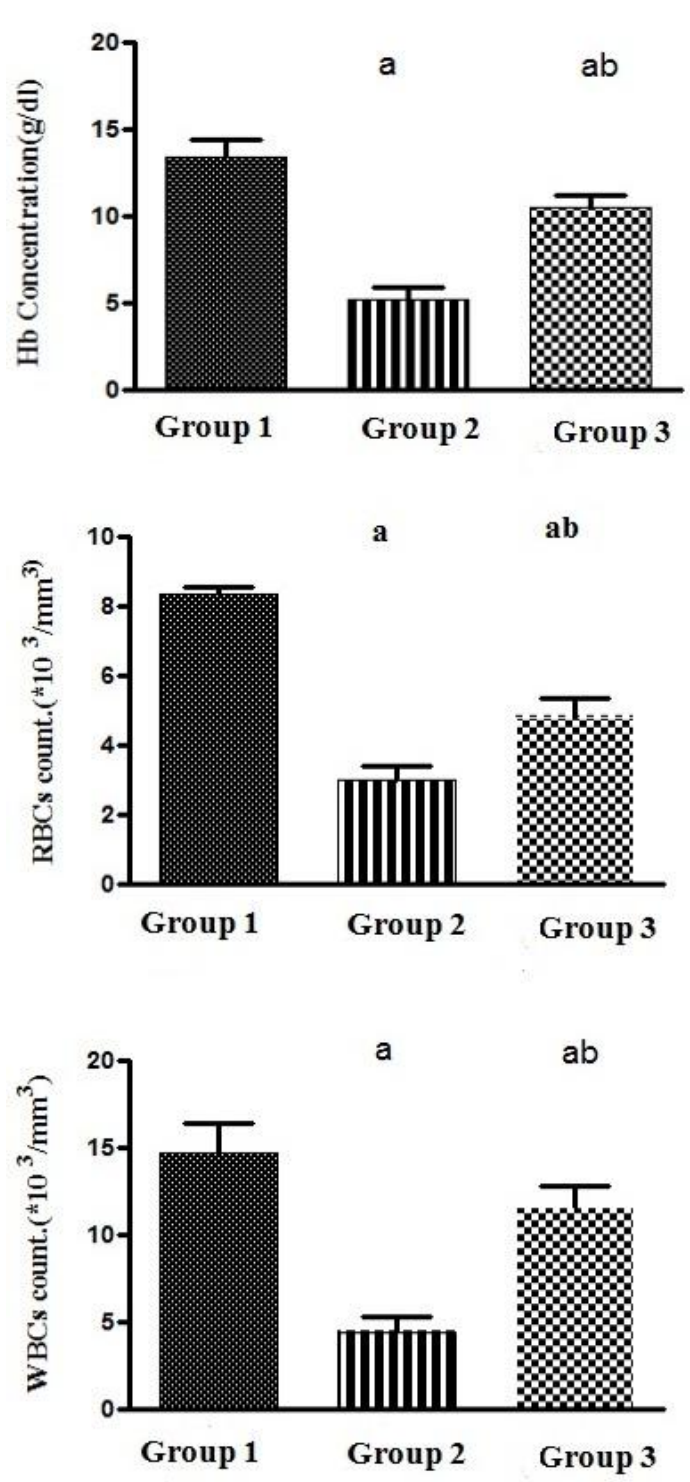

网 Group 1 Group 20 Group 3

Fig-1: Toxic effect of cyclophosphamides and the ameliorating effect of Sorgasum .Cinereum on RBCs, WBCs' count and $\mathrm{Hb}$ concentration. $\mathrm{P}<0.01$ compared with control values. Bars represent means $\pm \mathrm{SD}(\mathrm{N}=6)$.
(A)
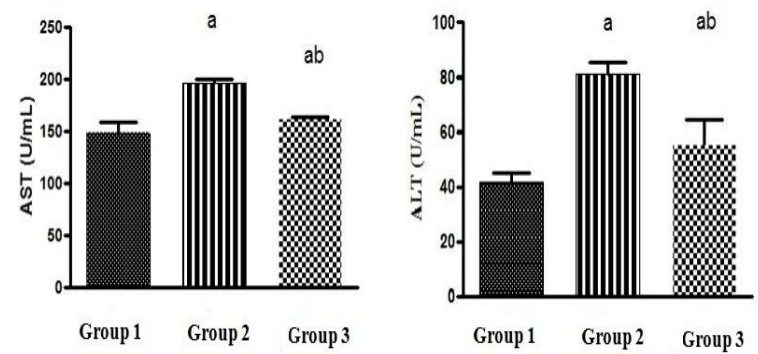

(B)
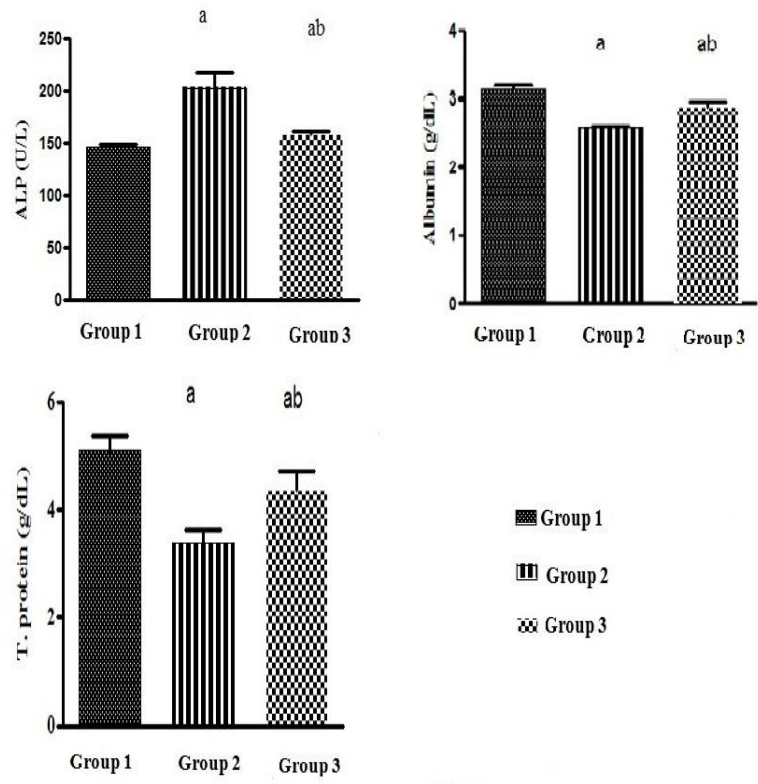

$$
\begin{aligned}
& \text { Group } 1 \\
& \text { Ш Group2 } \\
& \text { W Group } 3
\end{aligned}
$$

(C)

Fig-2: Serum liver enzymes activity (ALT, AST, ALP, Albumin and Total protein) in cyclophosphamides injected group and orally administered Sorgasum Cinereum group. $\mathbf{P}<0.01$ compared with control values. Bars represent means $\pm \mathrm{SD}(\mathrm{N}=6)$ 
$\mathrm{ab}$
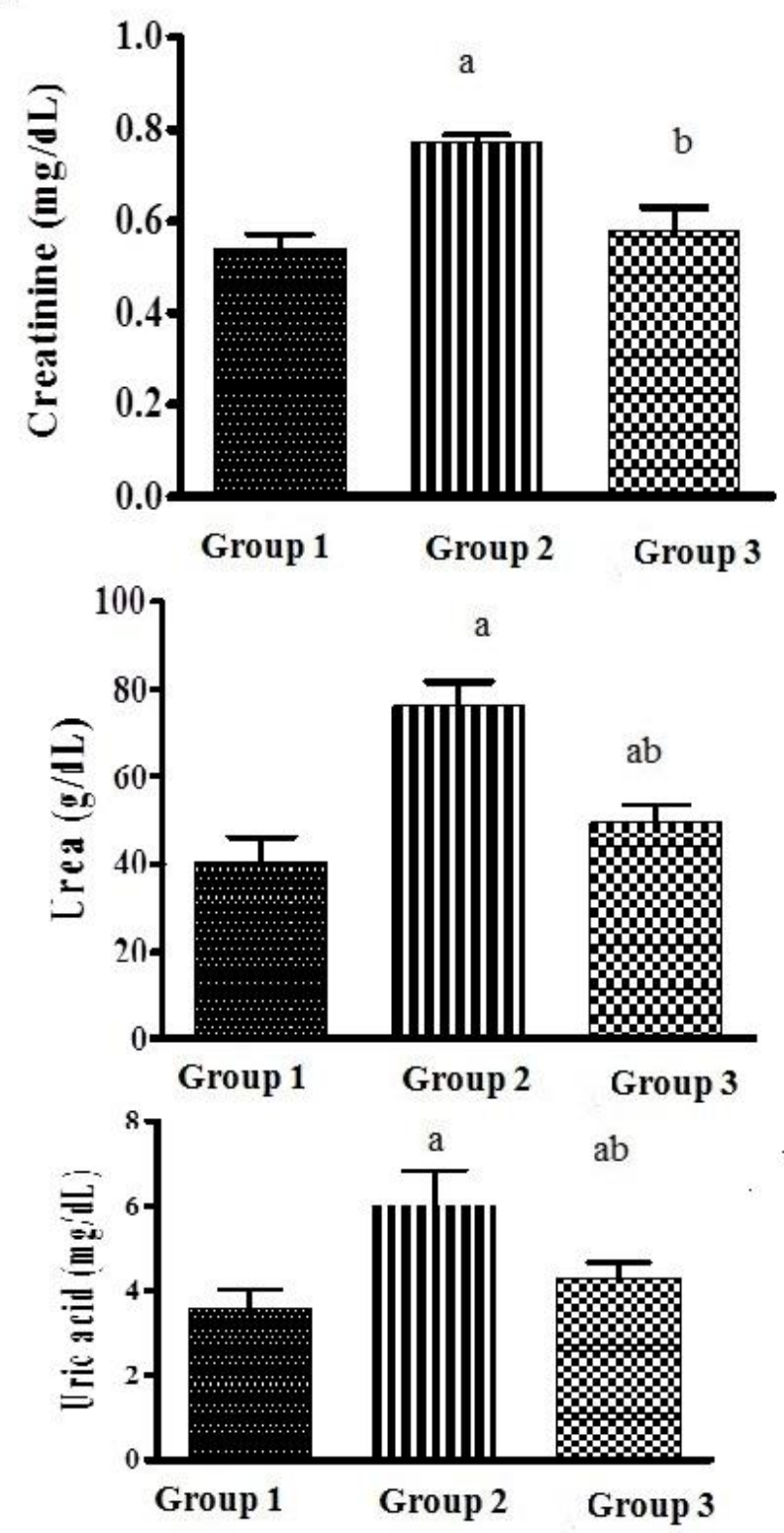

. Group 1

III Group 2 Group 3

Fig-3: Kidney function markers (creatinine, urea and uric acid) in cyclophosphamides injected group and orally administered Sorgasum Cinereum group. $\mathrm{P}<0.01$ compared with control values. Bars represent means $\pm \mathrm{SD}(\mathrm{N}=6)$.
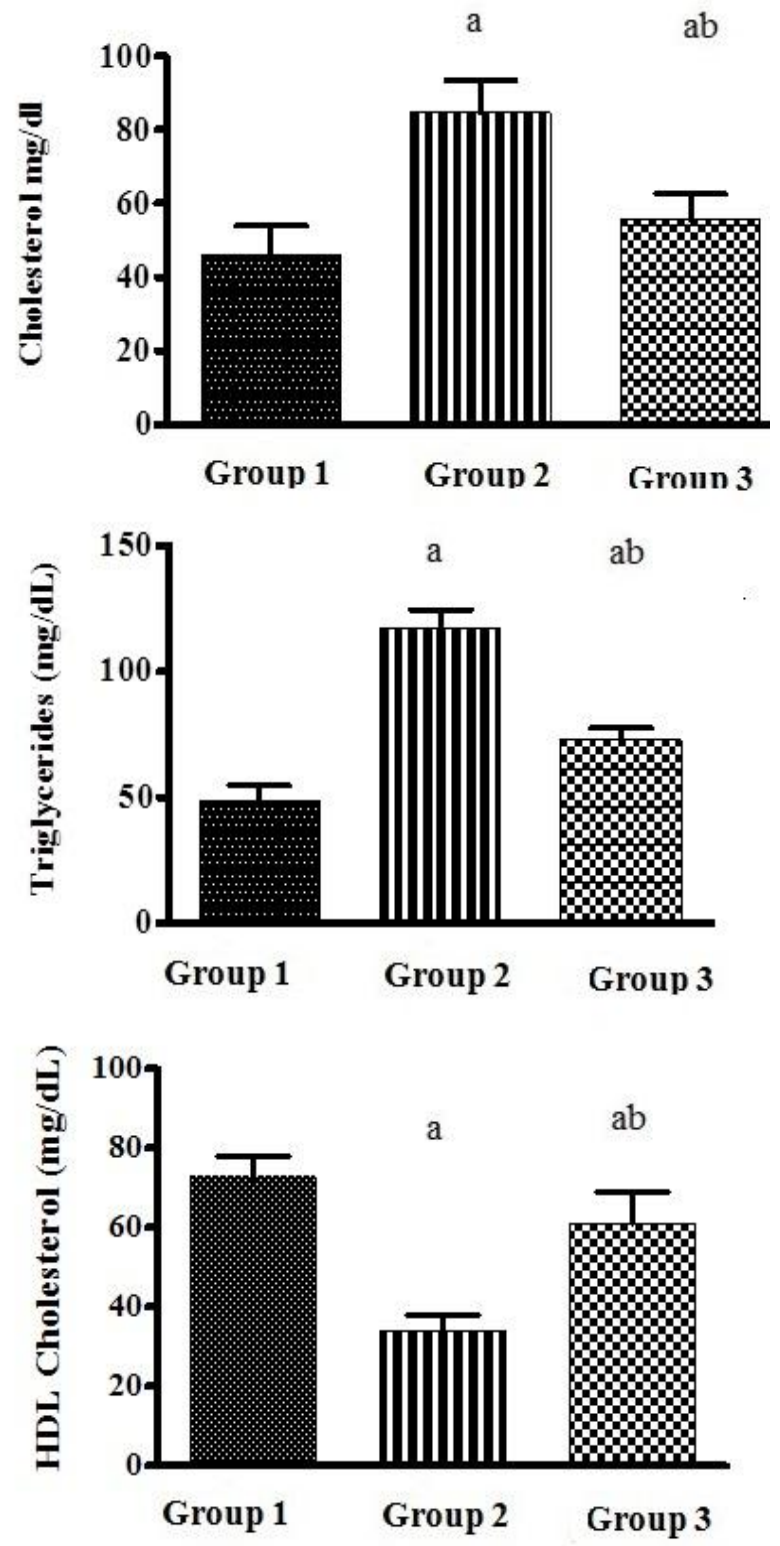

Group 1 Group 2 Group 3

Fig-4: Serum lipid profiles levels (Cholesterol, triglyceride and cholesterol-HDL) in cyclophosphamides injected group and orally administered Sorgasum Cinereum group. $\mathbf{P}<0.01$ compared with control values. Bars represent means $\pm \mathrm{SD}(\mathrm{N}=6)$ 


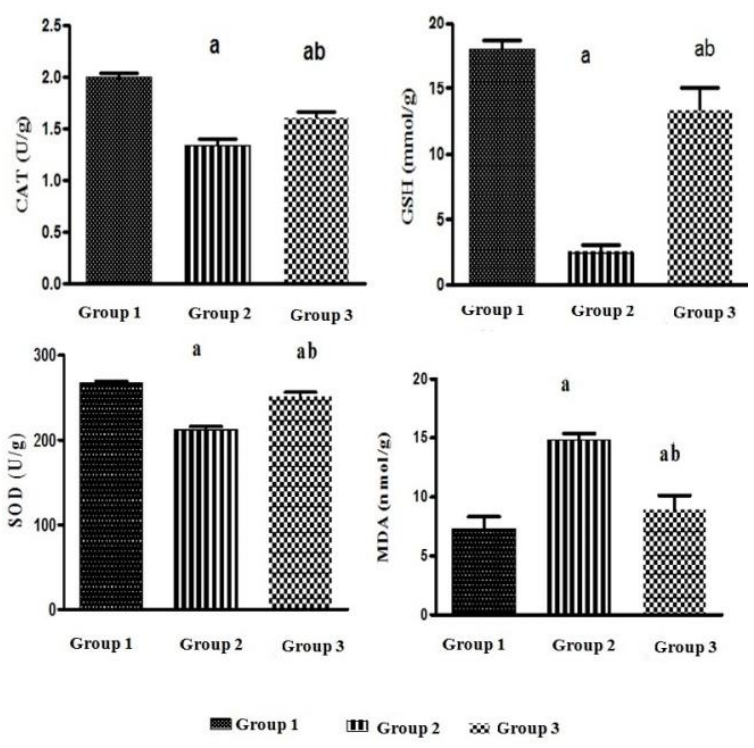

Fig-5: Effect of cyclophosphamides and the ameliorating effect of Sorgasum.Cinereum on the oxidative stress markers in liver homogenates (CAT, SOD, GSH and MDA). $\mathrm{P}<0.01$ compared with control values. Bars represent means $\pm S D(N=6)$.
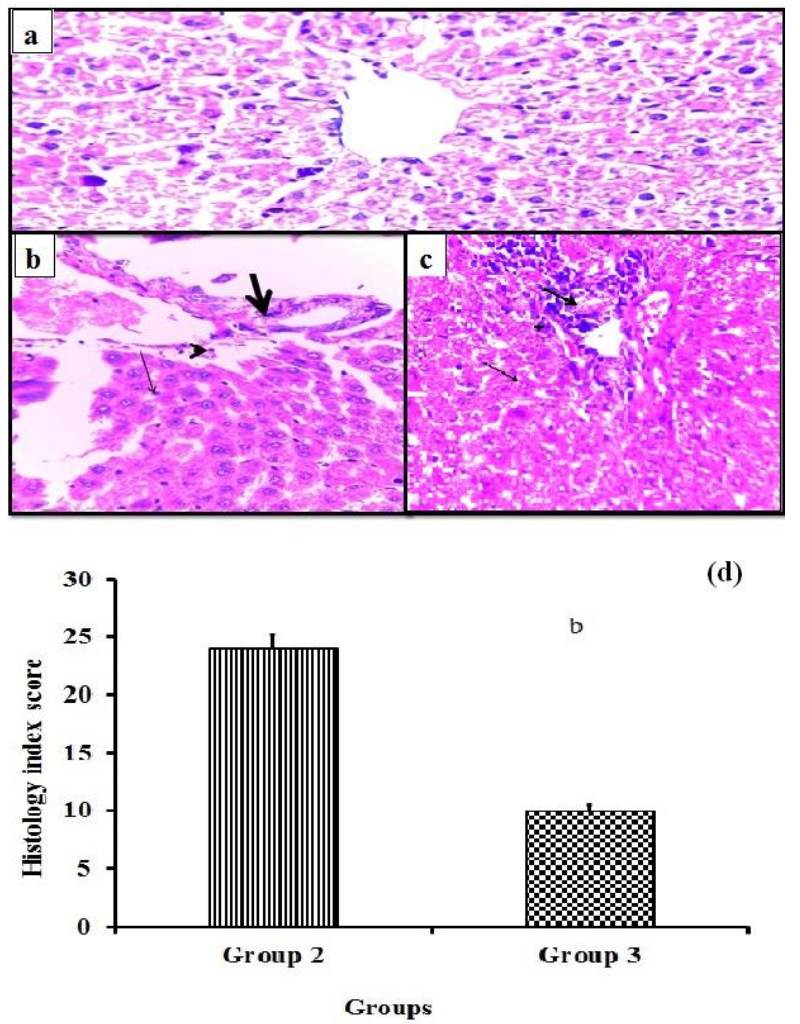

Fig-6: Histological changes (a,b and c) and in hematoxyline and eosine stained section in liver following $\mathrm{CP}$ injection (b) and oral administration of Sorgasum .Cinereum (c) in comparison to normal liver histology (a). Hepatotoxicity marked by necrosis in the hepatocytes (thin arrow) and in the portal triade associated with inflammatory cells infiltration (arrow head). Periportal fibrosis (thick arrow) evidenced around the hepatic lobules (b). Sorgasum .Cinereum induced restoration in the hepatic tissues evidenced by decrease in the hepatic cells necrosis and

inflammatory cells infiltrations (thick arrow). No marked fibrosis was seen around the portal triade (thin arrow). Histology index score (d) showing significant reduction in the histology index score after S.cinereum administration. $\mathrm{P}<0.01$ compared with control values. Bars represent means $\pm \mathrm{SD}(\mathrm{N}=6)$
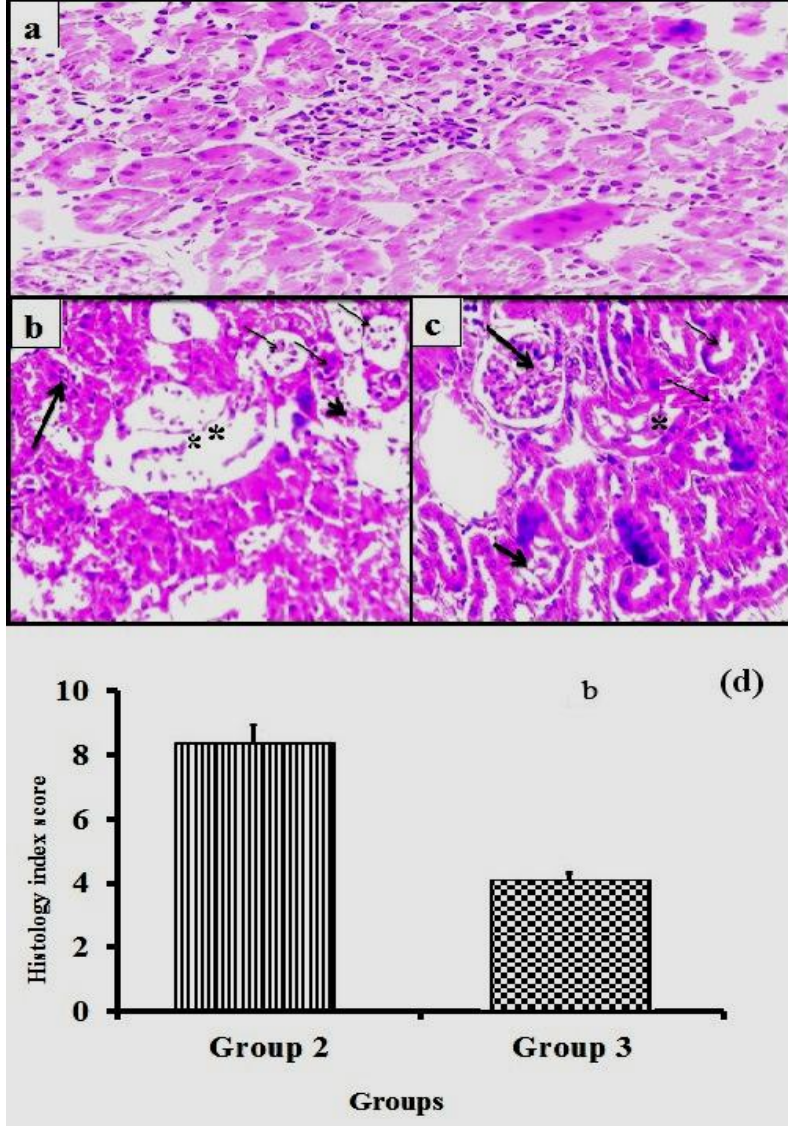

(d)

Fig-7: Histological changes (a,b and c) and in hematoxyline and eosine stained section in kidney following $\mathrm{CP}$ injection (b) and oral administration of Sorgasum .Cinereum (c) in comparison to normal kidney histology (a). Nephrootoxicity marked by necrosis in the glomeruli (thin arrow) and in the tubular epithelium

(Thick arrow), associated with inflammatory cells infiltration (arrow head). Renal tubules cystic dilation (Stars) was evidenced (b). Sorgasum .Cinereum induced recovery in the renal tissues evidenced by increase glomerular cells and decreases its necrosis (thick arrow) besides few inflammatory cells infiltrated (thick arrow). Histology index score (d) showing significant reduction in the histology index score after S.cinereum administration. $\mathrm{P}<0.01$ compared with control values. Bars represent means $\pm \mathrm{SD}(\mathrm{N}=6)$

\section{DISCUSSION}

The present study was done to expolre the toxic effects of Cyclophosphamide on the some hematological and biochemical parameters as well as liver and kidney tissues in albino rats besides to estimation of the ameliorating effects of S. cinereum against the $\mathrm{CP}$ toxicity.

In the present study injection of $\mathrm{CP}$ induced a significant decrease in the RBCs, WBCs' count and $\mathrm{Hb}$ concentration causing anemia and leucopenia. Same results obtained by Korkmaz et al. [23]. The decrease in the RBCs, WBCs' count and Hb concentration resulted from the direct toxic effect of cyclophosphamides on the bone marrow causing bone marrow suppression and myelotoxicity [24]. Moreover, the disrupted hematopoiesis may be returned to the indirect effect of cyclophosphamides hematopoietic system through the oxidative cells damage by free radical and reactive oxygen spices [25]. Oral administration of the $\mathrm{S}$. 
cinereum induced improvement in the blood parameters levels may be through activation of the antioxidative system.

$\mathrm{CP}$ injection exhibited significant hepatotoxic effects signed by the increased in the serum liver's enzymes ALT, AST and ALP activities. Additionally, hepatotoxicity also evidenced by decrease in the liver synthesis function represented by decrease of serum albumin and total proteins levels. The abnormal high level of liver enzymes observed in our study is the consequence of CP-induced liver dysfunction and hepatic cell damage. These observations are compatible with previous findings [26,12]. In accordance, the higher levels of serum liver's enzymes is indicative to the cellular damages and loss of functional integrity of the cell membrane of the hepatocytes [27]. In the hepatocellular lesions, hepatic enzymes are released from the liver into the bloodstream [28,26]. It is well known that liver has the dominant role in the biosynthesis of the plasma proteins [29]. In accordance injury to the hepatocytes impair plasma protein synthesis.

Using of the natural compounds as alternative medicine has been recommended because of relatively low costs and side effects when they compared to modern biochemical medicinal drugs [30]. Administration of $\mathrm{S}$. cinereum extract protected the liver against $\mathrm{CP}$-induced hepatotoxicity as it confirmed by lowering of serum level of these enzymes. In same line with the findings presented here, in a vitro study estimated that $\mathrm{S}$. cinereum extract has potent radical scavenging activity [20].

Furthermore, the toxicity by $\mathrm{CP}$ affected the kidney function and induced a significant increase in the serum urea, uric acid and creatinine following $\mathrm{CP}$ administration. It may be associated with the harmful effects on the hepatic tissues leads to a stage with characters of hepatorenal syndrome [31] the hepatorenal syndrome manifested by reduction in creatinine clearance and low glomerular filtration rate [32], in association with increase in the uric acid level. In the present study following to $\mathrm{CP}$ administration increase in the uric acid level may be due to a reduction in the glomerular filtration rate and renal urate excretion [33]. In accordance, production of of reactive oxygen species (ROS) by CP toxicity in the kidney tissues playing a critical role in the pathogenesis of renal injury [34] On the other hand, there is an improvement in the kidney functions after treatment with S. cinereum extract which may attriuted to its potent free radical scavengring activity.

Increase in the cholesterol and triglycerides levels with decrease in HDL-cholesterol level in the cyclophosphamide-treated group indicates that cyclophosphamide has the ability to change cholesterol profile which may be returned to oxidation of the cholesterol The rise in ROS generated by $\mathrm{CP}$ cause cellular cholesterol accumulation by increasing cholesterol biosynthesis and its esterification due to decreasing cholesteryl ester hydrolysis and reduction in the cholesterol efflux $[35,36]$. The animals treated with the seaweed extract prevented the elevation of total cholesterol and triglycerides. the natural protection of the lipids by the seaweed may be return to the presence some natural such as sulfated polysaccharide that may retard the intestinal absorption of cholesterol or speed up the cholesterol excretion [37]. Rats given S. cinereum exhibited improvement in the levels of HDL, which may be due to the ability of the extract to hurry the deactivation of the free radical species produced during cyclophosphamide administration.

For better understand of the hepatotoxic effect of the cyclophosphamides oxidative stress markers were detected. Oxidative stress is one of the mechanisms responsible for the liver damage and diseases progression. Comatition of the free radical and oxidative compunds minimizing its deteriorative effects was done by antioxidant [38]. Membrane lipids are more susceptible to free-radical damage. Lipids after reacting with free radicals undergos lipid peroxidation [39]. During cyclophosphamide injection, the production of free radicals may interrupt the oxidativeantioxidative balance present in the normal physiological status leading to oxidative stress. this may happen especially when the antioxidative system is not able to meet the overproduction of the reactive oxygen species [40]. Moreover, the cyclophosphamide metabolites such as acrolein. Acrolein is an $\alpha, \beta$ unsaturated aldehyde, that produces oxidative stress and increase in the lipid peroxidation and the formation of intracellular ROS such as superoxide anion radicals, hydroxyl radicals, and singlet oxygen. These reactive oxygen and nitrogen species injuries the cellular lipid, proteins, and DNA [41].

In our study, we find that intraperitoneal injection of CP-induced oxidative stress evidinced by significant decreases in the antioxidant enzymes such as SOD, GSH and CAT; and $t$ increased MDA production $[12,42]$, the changes in the oxidative stress markers may be attributed to the inactivation of the cellular antioxidants by the lipid peroxides and ROS produced during $\mathrm{CP}$ intoxication. Treatment of the rats with $\mathrm{S}$. cinereum enhanced the declined antioxidant enzyme activities. The restoration of the anti-oxidative power of the liver tissues returned to improvement of the antioxidant defense system due to free radical scavenging/anti-oxidant properties of the phytochemical contents present in S. cinereum. Other reports which suggest that extracts of brown seaweeds belonging to Sargassum spp. are anticipated to be very good inhibitors of lipid peroxidation [43, 44].

$\mathrm{CP}$ has great pathological effects on the liver and kidney. Intraperitoneal injection of cyclophosphamides induced both hepatic and renal 
toxicity manifested by many histolopathological changes includes necrosis in the hepatocytes and renal epithelium associated with inflammatory cells infiltration in both organs.

The histological changes oseved in the hepatic cells and blood vessels were due to the direct effect of the drug on the cells structures or may attributed to the free radicals production which caused cell membrane integrity of the hepatocytes [12]. Histological injuries in the hepatocytes give the explination of the biochemical results obtained in this study which represented by increase of the liver enzymes activity and the oxidative stress markers.

In accordance, the histopathological changes in the kidney following $\mathrm{CP}$ injection also were due to the direct effect of the toxins on the renal tuular epithelium increasing the cellular permeability of the glomeruli leading to decreased glomerular filtration rate and kidney function impairment. Recovery of the renal tissues histology was achived by oral administration of seaweed. This improvement and recovery may be due to the multi-beneficial properties of $S$ cinerarium extracts such as antioxidant and anti-inflammatory [45].

\section{CONCLUSION}

In conclusion, these results provide new evidences that toxic effect of CP is possibly mediated through depression the antioxidant system and subsequent cellular damage while the protective effect of S.cinereum mediated through the activation of this system and subsequent suppression of inflammatory and oxidative stress.

\section{REFERENCES}

1. Zhang, J., Tian Q., \& Zhou, S. (2006): Clinical pharmacology of cyclophosphamide and ifosfamide. Curr Drug Ther; 1: 55-84.

2. Dollery, C., \& Cyclophosphamide. (1999). In. Dollery C, (3 ${ }^{\text {rd }}$ Ed.), Therapeutic drugs. Edinburg'Churchill Livingstone, 349-353 .

3. Perini, P., Calabrese, M., Rinaldi, L., \& Gallo, P. (2007). The safety profile of cyclophosphamide in multiple sclerosis therapy. Expert Opin Drug Safety, 6: 183-90.

4. McDonald, G.B., Slattery J.T., \& Bouvier, M.E.(2003). Cyclophosphamide metabolism, liver toxicity, and mortality following hematopoietic stem cell transplantation. Blood.101:2043-2048.

5. Papaldo, P., Lopez, M., Marolla, P., Cortesi E., \& Antimi M. (2005). Impact of five prophylactic filgrastim schedules on hematologic toxicity in early breast cancer patients treated with Epirubicin and cyclophosphamide. J Clin Oncol. 23: 6908-18.

6. Amudha, G., Josephine, A., Mythili, Y., Sundarapandiyan, R., \& Varalakshmi, P. (2007). Therapeutic efficacy of dl-lipoic acid on cyclosporine A induced renal alterations. Eur J Pharmacol, 571: 209-14.
7. Morandi, P., Ruffini, P.A., Benvenuto, G.M., Raimondi, R. \& Fosser V. (2005). Cardiac toxicity of high-dose chemotherapy. Bone Marrow Transplant, 35: 323-34 .

8. Patti, F.1., \& Lo Fermo, S. (2011). Lights and shadows of cyclophosphamide in the treatment of multiple sclerosis. Autoimmune Dis, 961-702.

9. Sudharsan, P.T., Mythili, Y., Selvakumar, E., \& Varalakshmi, P. (2006). Lupeol and its ester exhibit protective role against cyclophosphamideinduced cardiac mitochondrial toxicity. J Cardiovasc Pharmacol, 47:205-210.

10. Manda, K., \& Bhatia, A.L. (2003). Prophylactic action of melatonin against cyclophosphamideinduced oxidative stress in mice. Cell Biol Toxicol, 19: 367-72.

11. Alenzi, F.Q., El-Bolkiny, Yel-S., \& Salem, M.L. (2010). Protective effects of Nigella sativa oil and thymoquinone against toxicity induced by the anticancer drug cyclophosphamide. $\mathrm{Br} \mathrm{J}$ Biomed Sci, 67: 20-8.

12. Germoush, M.O., \& Mahmoud, A.M. (2014). Berberine mitigates cyclophosphamide-induced hepatotoxicity by modulating antioxidant status and inflammatory cytokines.J Cancer Res Clin Oncol, 140:1103-9.

13. Ghosh, M. (1999). Pathways of As(III) detoxification in Saccharomyces cerevisiae. Proc Natl Acad Sci U S A. 96:5001-6.

14. Senthilkumar, S., Yogeeta, S.K., Subashini, R., \& Devaki T. (2006). Attenuation of cyclophosphamide induced toxicity by squalene in experimental rats. Chem-Biol. Interact; 160: 252 260.

15. West, N.J. (1997). Prevention and treatment of hemorrhagic cystitis. Pharmacotherapy. 17:696706.

16. Ayhanci, A., Yaman, S., Sahinturk, V., Uyar, R., \& Bayramoglu, G. (2010). Protective effect of selenoL-methionine on cyclophosphamide-induced urinary bladder toxicity in rats. Biol Trace Elem Res; 134: 98-108.

17. Fraser, C.I. (2012). The role of common names in science. NZJ Mar Freshw Res. 46:279-84 .

18. Kang, K., Park, Y., Hwang, H.J., Kim, S.H., \& Lee, J.G. (2003). Antioxidative Properties of Brown Algae Polyphenolics and Their Perspectives as Chemopreventive Agents Against Vascular Risk Factors. Arch Pharm Res. 26:286-293.

19. Somasundaram, S.N., Shanmugam, S., Subramanian, B., \& Jaganathan, R. (2016). Cytotoxic effect of fucoidan extracted from Sargassum cinereum on colon cancer cell line HCT-15. Int J Biol Macromol;91:1215-23.

20. Mole, M., \& Sabale, A. (2013). Antioxidant Potential of Seaweeds from Kunakeshwar along the West Coast MaharashtraAsian Journal of Biomedical and Pharmaceutical Sciences, 3: 45-50.

21. Chan, Y.Y., Kim, K.H., \& Cheah, S.H. (2011). Inhibitory effects of Sargassum polycystum on 
tyrosinase activity and melanin formation in B16F10 murine melanoma cells. J Ethnopharmacol, 137: 1183-8.

22. Zhang, L.Q., \& Dietrich, R. (2008). Prevalence of chronic kidney disease in population-based studies: Systematic review BMC Public Health. 8:117.

23. Korkmaz, A., Topal, T., \& Oter, S.(2007). Pathophysiological aspects of cyclophosphamide and ifosfamide induced hemorrhagic cystitis; implication of reactive oxygen and nitrogen species as well as PARP activation. Cell Biol Toxicol, 23 :303-12.

24. Friberg, L.E., Henningsson, A., Maas, H., Nguyen L., \& Karlsson, M.O. (2002). Model of chemotherapy-induced myelosuppression with parameter consistency across drugs. J Clin Oncol, 20: 4713-21.

25. Hinson, J.A., Bucci, T.J., Irwin, L.K., Michael, S.L., \& Mayeux, P. R.(2002). Effect of inhibitors of nitric oxide synthase on acetaminophen-induced hepatotoxicity in mice. Nitric Oxide.6, 160-167.

26. Selvakumar, E., Prahalathan, C., Mythili Y., \& Varalakshmi, P. (2005). Mitigation of oxidative stress in cyclophosphamide-challenged hepatic tissue by DL-alpha-lipoic-acid. Mol Cell Biochem. 272:179-185

27. Kumar, G., Banu, S.G, Kannan, V., \& Pandian, R.M.(2005). Antihepatotoxic effect of $\beta$-carotene on paracetamol induced hepatic damage in rats. Ind J Exp Biol.43 : 351-355.

28. Plaa, G.L., \& Hewitt, W.R. (2014). Detection and evolution of chemically induced liver injury. In: Hayes AW, Claire LK, editors. Hayes' Principles and Methods of Toxicology A.W. Hayes $\left(6^{\text {th }}\right.$ ed). Raven press, New York, 401-441.

29. Miller, L.L., Bly, C.G., \& Watson, W.F.(1951). the dominant role of the liver in plasma protein synthesis . J Exp Med. 94:431-53

30. Hu, X., Sato J., Oshida, Y., Yu, M., Bajotto, G., \& Sato, Y.( 2003). Effect of Goshajinki gan (Chinese herbal medicine): Niu-che-sen.qi-wan) on insulin resistance in streptozocin induced diabetic rats. Diab Res in Clin Pract.59: 103-111.

31. Arroyo, V., \& Jiménez, W.(2000). Complications of cirrhosis. II. Renal and circulatory dysfunction. Lights and shadows in an important clinical problem, J Hepatol. 32:157-70.

32. Brigalia, A., \& Anania, F. (2002). Hepatorenal syndrome - Definition, pathophysiology, and intervention. Critical Care Clinics, 18:345-73.

33. Vaziri, N.D., Freel, R.W., \& Hatch, M. (1995). Effect of chronic experimental renal insufficiency on urate metabolism. J Am Soc Nephrol. 6:1313-7.

34. Abraham, P., \& Rabi, S. (2011). Aminoguanidine, a selective nitric oxide synthase inhibitor, attenuates cyclophosphamide-induced renal damage by inhibiting protein nitration and poly(ADP-Ribose) polymerase activation. Chemotherapy, 57: 327-334.

35. Gesquière, L., Loreau, N., Minnich, A., Davignon, J., \& Blache, D. (1999). Oxidative stress leads to cholesterol accumulation in vascular smooth muscle cells. Free Radic Biol Med, 27:134-45.

36. Asiri, Y.A.(2010). Probucol attenuates cyclophosphamide-induced oxidative apoptosis, p53 and Bax signal expression in rat cardiac tissues. Oxid Med Cell Longev, 3: 308-16.

37. Raghavendran, H.R., Sathivel, A., \& Devaki, T. (2005). Effect of Sargassum polycystum (Phaeophyceae)-sulfated polysaccharide extract against acetaminophen-induced hyperlipidemia during toxic hepatitis in experimental rats. Mol. Cell. Biochem, 276: 89-96.

38. Surapaneni, K.M., \& Jainu, M. (2014). Comparative effect of pioglitazone, quercetin and hydroxy citric acid on the status of lipid peroxidation and antioxidants in experimental nonalcoholic steatohepatitis. J Physiol Pharmacol, 65:67-74.

39. Devasagayam, T.P.A., Tilak, J.C., Boloor, K.K., Sane, S.K., \& Ghaskadbi S.S. (2004). Free radicals and antioxidants in human health: Current status and future prospects. J Assoc Phys India. 52: 794804.

40. Stankiewicz, A., \& Skrzydlewska, E. (2003). Protection against cyclophosphamide-induced renal oxidative stress by amifostine: the role of antioxidative mechanisms. Toxicol Mech Methods, 13:301-8.

41. Patel, J.M., \& Block, E.R. (1985). Cyclophosphamide-induced depression of the antioxidant defense mechanisms of the lung. Exp. Lung Res, 8: 153-165.

42. Kouidhi, S., Rouissi, K., Hamrita, B., Ouerhani, S., $\&$ Cherif, M. (2012). Therapeutic effects of aloe Vera plant extract against cyclophosphamide and buthionine sulfoximine induced toxicities in the bladder. Biochem Pharmacol. 1: 1-4.

43. Meena, B., Anbin Ezhilan, R., Rajesh, R., Sheik Hussain, A., \& Ganesan, B. (2008). Antihepatotoxic potential of Sargassum polycystum (Phaeophyceae) on antioxidant defense status in Dgalactosamine- induced hepatitis in rats. Afr. J. Biochem. Res, 2: 051-055.

44. Zhang, R.L., Luo, W.D., Bi T.N., \& Zhou, S.K. (2012). Evaluation of antioxidant and immunityenhancing activities of Sargassum pallidum aqueous extract in gastric cancer rats. Molecules. 17: 8419-29.

45. Pngestuti, R., \& Kim, S.K. (2011). Biological Activities and Health Benefit Effects of Natural Pigments Derived from Marine Algae. Journal of Functional Foods. 3: 255-266. 